\title{
Low serum 25-hydroxyvitamin D [25(OH)D] concentrations in type 2 diabetes mellitus patients presenting to a functional medicine clinic
}

\author{
Paul A. Oakley ${ }^{1}$, Stephanie J. Chaney ${ }^{2}$, Michael A. Persinger ${ }^{3}$, Thomas A. Chaney ${ }^{2}$ \\ ${ }^{1}$ Private Practice, Newmarket, Canada \\ ${ }^{2}$ Private Practice, Annapolis, USA \\ ${ }^{3}$ Behavioral Neuroscience Program, Laurentian University, Sudbury, Canada \\ Email: docoakley.icc@gmail.com
}

Received 5 March 2013; revised 7 April 2013; accepted 8 May 2013

Copyright (C) 2013 Paul A. Oakley et al. This is an open access article distributed under the Creative Commons Attribution License, which permits unrestricted use, distribution, and reproduction in any medium, provided the original work is properly cited.

\begin{abstract}
This study explores the relationship of 25-hydroxylvitamin D blood levels in 106 randomly selected patient files with diagnosed type 2 Diabetes Mellitus (t2DM) who enrolled in a functional medicine diabetes reversal program from a chiropractic clinic located in Annapolis, Maryland, USA. Using a conservative recommendation for normal serum 25-hydroxyvitamin D concentration of $32 \mathrm{ng} / \mathrm{ml}$, insufficiency level of 20 - $30 \mathrm{ng} / \mathrm{ml}$, and deficiency level $<20$ $\mathrm{ng} / \mathrm{ml}, 21 \%(22 / 106)$ of our population were normal, $39 \%(41 / 106)$ were insufficient, and alarmingly, $35 \%$ (37/106) were outright deficient. Clinically, $74 \%$ (78/ 106) of our entire sample had significantly low vitamin D levels. Ou et al. (2011) determined the optimal concentration of serum $250 \mathrm{HD}$ to be $40 \mathrm{ng} / \mathrm{ml}$ in order to optimize insulin sensitivity. In our sample 100/ $106(94 \%)$ had vitamin D levels at or below this optimal cut-off level. BMI was negatively correlated with vitamin D; that is, the greater the BMI of the patient the less their vitamin D level. Both obesity and hypovitaminosis $D$ are each mutually exclusive predictors for t2DM. Obesity and vitamin D deficiency may work synergistically to propel an individual into the diseased state of t2DM. As this study demonstrates that the majority of people with t2DM suffer from inadequate amounts of vitamin $D$, vitamin $D$ testing should be routine for all people at risk for t2DM, prediabetics and those currently suffering with t2DM in order to elevate levels sufficiently to improve insulin sensitivity and improve long-term outcomes.
\end{abstract}

Keywords: Diabetes Mellitus; BMI; Vitamin D; Deficiency; Insufficiency; Functional Medicine

\section{INTRODUCTION}

Vitamin D was originally misclassified as merely a vitamin when indeed it is a hormone and involved in a plethora of physiological processes. Its insufficiency or outright deficiency is implicated in not only bone fractures and osteoporosis but also numerous serious and often fatal diseases, including many cancers, infectious diseases, heart disease, autoimmune and metabolic diseases including type 2 Diabetes Mellitus (t2DM).

Vitamin D status has been verified to be inversely associated with future risks of t2DM [1]. Vitamin D status in t2DM patients is associated with glucose and lipid parameters [2]. This study explores the relationship of vitamin $\mathrm{D}$ blood levels in those with diagnosed t2DM upon first presentation to a functional medicine diabetes reversal program.

\section{METHODS}

\subsection{Subjects}

106 t2DM patients were randomly selected out of the files of a functional medicine and chiropractic clinic located in Annapolis, Maryland, USA. Sixty of the subjects were Black, 41 were Caucasian, and 5 were Asian.

The patients had presented to the office for enrolment into a t2DM reversal program during the years 20112012. All patients had been previously diagnosed with t2DM by an MD or Endocrinologist and were taking either oral medication for glucose control or by injecting insulin.

\subsection{Parameters Investigated}

Initial consultation and examination involved the routine assessment of serum 25-hydroxy vitamin D concentra- 
tion (ng/ml). This was referred out to a local blood lab. Vitamin D blood levels were investigated for differences in gender, height, weight, BMI, race and age and also how these population averages compare to "normal" ( $\geq 32 \mathrm{ng} / \mathrm{ml})$ [3], "insufficient" (20 - $30 \mathrm{ng} / \mathrm{ml})$ [4] and "deficient" ( $<20 \mathrm{ng} / \mathrm{ml})[4,5]$ values.

\section{RESULTS}

The 106 patient files review consisted of 61 females and 45 males (Table 1). The average age was $58.6( \pm 9.3)$ years, height was $171.2 \mathrm{~cm}( \pm 9.7)$, weight was $95.5 \mathrm{~kg}$ $( \pm 20.0)$, and BMI was $32.6( \pm 6.2)$. The average serum 25-hydroxy vitamin D concentration was $24.5 \mathrm{ng} / \mathrm{ml}$ ( \pm 9.2 ). Twenty-one percent, $39 \%$ and $35 \%$ of the sample fell into categories of normal $(\geq 32 \mathrm{ng} / \mathrm{ml})$, insufficient (20 - $30 \mathrm{ng} / \mathrm{ml})$, and deficient $(<20 \mathrm{ng} / \mathrm{ml})$, respectively.

Two-way analysis of variance as a function of race and gender displayed only statistically significant gender differences. As there were few Asians in our sample ( $\mathrm{n}=$ 5 ), only Blacks and Caucasians were considered for racial difference. There were no statistically significant differences in vitamin $\mathrm{D}$ between race $(\mathrm{F}=1.59, \mathrm{p}=0.21)$ nor was there a gender by race interaction. In other words there was no differential gender effect between the races. When height is covaried; that is, the correlation between vitamin D levels and height is first removed, there is still no emergence of racial differences or racial by sex interactions.

To discern potential hidden variables, partial correlations were completed. Vitamin D levels were significantly correlated negatively with BMI (rho $=-0.21, \mathrm{p}<$ 0.05 ) (Figure 1) and positively correlated with height (rho $=0.25, \mathrm{p}<0.05$ ) (Figure 2).

Since gender was the only primary and persistent statistically significant effect, one-way analyses were completed for each variable. Only height and BMI were significant statistically, where males were taller $(\mathrm{F}=34.9, \mathrm{p}$ $<0.01)$ and had a greater BMI $(\mathrm{F}=5.9, \mathrm{p}<0.05)$.

\section{DISCUSSION}

We explored the relationship of serum 25-hydroxyvita-

Table 1. Mean, standard deviation, minimum, and maximum values for age (years), height $(\mathrm{cm})$, weight $(\mathrm{kg}), \mathrm{BMI}\left(\mathrm{kg} / \mathrm{m}^{2}\right)$, and serum 25 -hydroxyvitamin D concentration (d level: $\mathrm{ng} / \mathrm{ml}$ ).

\begin{tabular}{ccccc}
\hline Variable & Mean & Std. Dev. & Minimum & Maximum \\
\hline Age $(\mathrm{yrs})$ & 58.6 & 9.3 & 35.0 & 80.0 \\
Height $(\mathrm{cm})$ & 171.2 & 9.7 & 147.3 & 195.6 \\
Weight $(\mathrm{kg})$ & 95.5 & 20.0 & 58.5 & 150.6 \\
BMI $\left(\mathrm{kg} / \mathrm{m}^{2}\right)$ & 32.6 & 6.2 & 21.8 & 53.6 \\
d level $(\mathrm{ng} / \mathrm{ml})$ & 24.5 & 9.2 & 7.0 & 45.5 \\
\hline
\end{tabular}

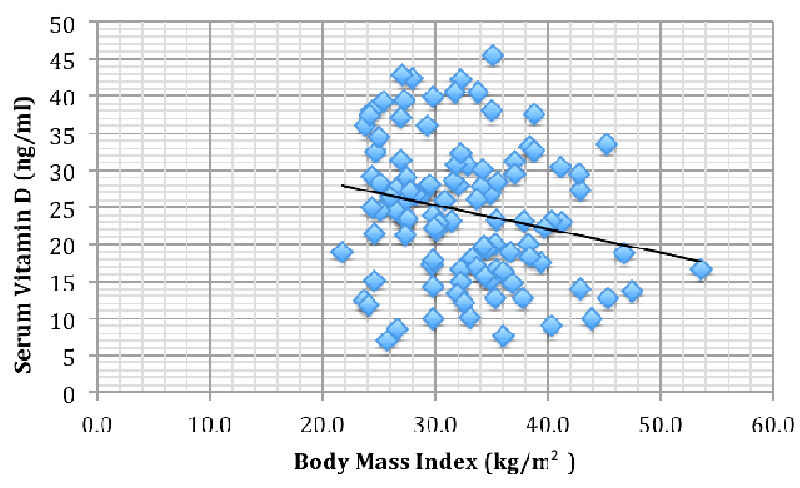

Figure 1. Body mass index $\left(\mathrm{kg} / \mathrm{m}^{2}\right)$ vs serum 25-hydroxyvitamin D concentration $(\mathrm{ng} / \mathrm{ml})$ were significantly correlated rho $=-0.21, \mathrm{p}<0.05$.

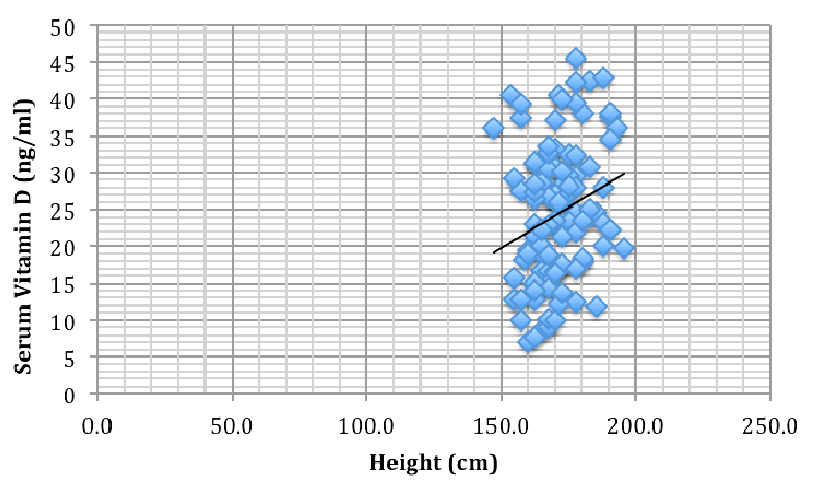

Figure 2. Height (cm) vs serum 25-hydroxyvitamin D concentration $(\mathrm{ng} / \mathrm{ml})$ were significantly correlated rho $=0.25, \mathrm{p}<0.05$.

min D concentrations in a random sample of $106 \mathrm{t} 2 \mathrm{DM}$ patients who presented to a functional medicine diabetes reversal program during the years 2011 and 2012 from a clinic located in Annapolis, Maryland, USA. All the patients had been diagnosed with adult onset, type 2 Diabetes Mellitus by either their primary medical doctor or an endocrinologist.

A conservative recommendation for serum 25-hydroxyvitamin D concentration is $32 \mathrm{ng} / \mathrm{ml}$ [3]. Our sample average was well below this level, in fact, only 22/ $106(21 \%)$ had healthy levels. Thirty nine percent of the sample (41/106) were "insufficient", and alarmingly, one third were outright "deficient" 37/106 (35\%). Thus, overall $74 \%(78 / 106)$ of our entire sample had clinically significantly low vitamin $\mathrm{D}$ levels.

Although there may be debate as to an actual single optimal vitamin D level, if we consider a normal "functional" range between 30 to $74 \mathrm{ng} / \mathrm{ml}$, (suppose an average of $52 \mathrm{ng} / \mathrm{ml}$; SD $=11$ ), relative to this our population would be 2.75 Standard deviations below the normal mean level. These results coincide with the findings of others finding very low vitamin D levels in groups of diabetic patients [6-8].

Considering vitamin D deficiency increases the risk of all-cause and cardiovascular mortality in t2DM patients 
[9], this is very concerning. Further, Annapolis, MD is located at $38^{\circ}$ latitude, it is alarming to consider the blood levels of vitamin D in other t2DM patients living northward and into Canada as latitude effects on vitamin D status is a well known phenomenon [10].

Our results and others demonstrate that serum vitamin D levels in t2DM patients are typically low. Vitamin D has been shown in research to play an important role in insulin resistance as well as impaired beta cell function, the main issues with $\mathrm{t} 2 \mathrm{DM}$ [11].

Hypovitaminosis D has long been suspected as a risk factor for glucose intolerance [12]. Once theorized that glucose tolerance could adversely affect insulin sensitivity and beta-cell function [13], this was directly proven by Chiu et al. [12] in 126 glucose-tolerant subjects.

Therefore, the rationale for supplementation of vitamin D for t2DM patients is substantiated. Vitamin D supplementation has been proven to reduce the risk of developing the disease [14], as well as to reverse the disease state altogether [15-17].

The mechanisms underlying the improvements in glucose tolerance are less understood, but are thought to be due to vitamin D's effects on both insulin production and sensitivity $[12,18]$. More specifically, the mechanisms underlying improved glucose response to vitamin D may lie in potential relationships with improvements in lean mass, regulation of insulin release, altered insulin receptor expression and specific effects on insulin action [19].

There were no racial differences between the Caucasian and black samples as may be expected [20,21]. This is undoubtedly due to the fact that our entire sample of t2DM patients had very low levels of vitamin D (mean $24 \mathrm{ng} / \mathrm{ml}$ ), and as discussed this very population typically has low levels despite racial orientation.

It was determined that the taller the patient, the greater the vitamin $\mathrm{D}$ levels in our sample ( $\mathrm{rho}=0.25, \mathrm{p}<0.05$ ). Height is not expected to correlate to vitamin D status for any rationale reason and because of this, we assume that although statistically significant, this is merely a coincidental finding in our particular sample.

Our sample did not demonstrate any significant age and vitamin D level association. Age, however would be expected to negatively correlate with vitamin D status since older individuals are less efficient at producing vitamin D in sunlight as opposed to younger individuals as well as the fact that older individuals kidneys are less able to convert vitamin D into its active form [22].

BMI was negatively correlated with vitamin $\mathrm{D}($ rho $=$ $-0.21, \mathrm{p}<0.05$ ); that is, the greater the BMI of the patient the less their vitamin D level. Both obesity and hypovitaminosis $\mathrm{D}$ are each mutually exclusive predictors for t2DM $[23,24]$. Further each has an exacerbated effect on the other. Gonzalez-Molero et al. (2013) [23] for example, determined that subjects with vitamin D deficiency were significantly associated with developing obesity within the next four years. Alternatively, those who are obese have greater requirements for vitamin D [24].

Obesity and vitamin D deficiency may work synergistically to propel an individual into the diseased state of t2DM. The average BMI in our sample was 32.6 (6.2), which by definition is on average, an obese group (BMI $>30$ ). The average vitamin $\mathrm{D}$ level in our group was 24.5 $\mathrm{ng} / \mathrm{ml}(9.2)$, very clinically low.

Ou et al. (2011) [24] determined the optimal concentration of serum $25 \mathrm{OHD}$ to be $40 \mathrm{ng} / \mathrm{ml}$ in order to optimize insulin sensitivity. In our sample 100/106 (94\%) had vitamin D levels at or below this optimal cut-off level.

Because the overweight and obese with hypovitaminosis D may benefit more than normal weight subjects, the use of vitamin D supplementation as first-line treatment would be logical. In fact, it has been determined that an increase in vitamin D serum levels from 10 to 30 $\mathrm{ng} / \mathrm{ml}$ increases insulin sensitivity by $60 \%$ [12]. As Chiu et al. [12] note, a $60 \%$ improvement in insulin sensitivity is more potent than the medications of troglitazone (54\% improvement [25]) and metformin (13\% improvement [25]).

As this study demonstrates that the majority of people with t2DM suffer from inadequate amounts of vitamin D, vitamin D testing should be routine for all people at risk for t2DM, pre-diabetics and those currently suffering with $\mathrm{t} 2 \mathrm{DM}$ in order to elevate levels sufficiently to improve insulin sensitivity and improve long-term outcomes [15-18,26].

It should be no surprise that those at risk for diabetes are the same as those at risk for low vitamin D including the elderly, those living indoors, dressing in a covered-up style, dark-skinned individuals, and the obese [22,27]. The evidence has become overwhelming for the safe, cost-effective addition for vitamin D supplementation as a first line approach in the treatment and management of type 2 diabetes. Large scale, well-controlled clinical trials assessing the effects of vitamin D treatment in this disorder are overdue and warranted.

\section{CONCLUSION}

Type 2 Diabetes Mellitus patients typically have low vitamin D serum levels that perpetuate and worsen patient outcomes. Large scale, well-controlled clinical trials assessing the effects of vitamin D treatment in this disorder are overdue and warranted.

\section{REFERENCES}

[1] Kahn, H., Kunutsor, S., Franco, O.H. and Chowdhury, R. 
(2013) Vitamin D, type 2 diabetes and other metabolic outcomes: A systematic review and meta-analysis of prospective studies. Proceedings of the Nutrition Society, 72, 89-97. doi:10.1017/S0029665112002765

[2] Yu, J.R., Lee, S.A., Lee, J.G., Seong, G.M., Ko, S.J., Koh, G., et al. (2010) Serum vitamin D status and its relationship to metabolic parameters in patients with type 2 diabetes mellitus. Chonnam Medical Journal, 48, 108-115. doi: $10.4068 / \mathrm{cmj} .2012 .48 .2 .108$

[3] Hollis, B.W. (2005) Circulating 25-hydroxyvitamin levels indicative of vitamin D sufficiency: Implications for establishing a new effective dietary intake recommendation for vitamin D. Journal of Nutrition, 135, 317-22.

[4] Holick, M.F. (2008) Diabetes and the vitamin D connection. Current Diabetes Reports, 8, 393-398. doi:10.1007/s11892-008-0068-0

[5] (2010) Standing committee on the scientific evaluation of dietary reference intakes. Dietary reference intakes for vitamin D and calcium. National Academy Press, Washington DC.

[6] Scragg, R., Holdaway, I., Singh, V., Metcalf, P., Baker, J. and Dryson, E. (1995) Serum 25-hydroxyvitamin D3 levels decreased in impaired glucose tolerance and diabetes mellitus. Diabetes Research and Clinical Practice, 27, 181-188. doi:10.1016/0168-8227(95)01040-K

[7] Pietschmann, P., Schernthaner, G. and Woloszczuk, W. (1988) Serum osteocalcin levels in diabetes mellitus: Analysis of the type of diabetes and microvascular complications. Diabetologia, 31, 892-895. doi:10.1007/BF00265373

[8] Isaia, G., Giorgino, R. and Adami, S. (2001) High prevalence of hypovitaminosis $\mathrm{D}$ in female type 2 diabetic population. Diabetes Care, 24, 1496. doi:10.2337/diacare.24.8.1496

[9] Joergensen, C., Gall, M.A., Schmedes, A., Tarnow, L., Parving, H.H. and Rossing, P. (2010) Vitamin D levels and mortality in type 2 diabetes. Diabetes Care, 33, 2238-2243. doi:10.2337/dc10-0582

[10] McKenna, M.J. (1992) Differences in vitamin D status between countries in young adults and the elderly. American Journal of Medicine, 93, 69-77. doi:10.1016/0002-9343(92)90682-2

[11] Abdul-Ghani, M.A., Tripathy, D. and DeFronzo, R.A. (2006) Contributions of beta-cell dysfunction and insulin resistance to the pathogenesis of impaired glucose tolerance and impaired fasting glucose. Diabetes Care, 29, 1130-1139. doi: $10.2337 / \mathrm{dc} 05-2179$

[12] Chiu, K.C., Chu, A., Go, V.L. and Saad, M.F. (2004) Hypovitaminosis D is associated with insulin resistance and beta cell dysfunction. The American Journal of Clinical Nutrition, 79, 820-825.

[13] Rosetti, L., Giaccari, A. and DeFronzo, R.A. (1990) Glucose toxicity. Diabetes Care, 13, 610-630. doi:10.2337/diacare.13.6.610

[14] Pittas, A.G., Dawson-Hughes, B., Li, T., Van Dam, R.M., Willett, W.C., Manson, J.E. and Hu, F.B. (2006) Vitamin
$\mathrm{D}$ and calcium intake in relation to type 2 diabetes in women. Diabetes Care, 29, 650-656. doi:10.2337/diacare.29.03.06.dc05-1961

[15] Schwalfenberg, G. (2008) Vitamin D and diabetes. Canadian Family Physician, 54, 864-866.

[16] Kumar, S., Davies, M., Zakaria, Y., Mawer, E.B., Gordon, C., Olukoga, A.O. and Boulton, A.J.M. (1994) Improvement in glucose tolerance and beta-cell function in a patient with vitamin $\mathrm{D}$ deficiency during treatment with vitamin. Postgraduate Medical Journal, 70, 440-443. doi:10.1136/pgmj.70.824.440

[17] Chaney, S., Chaney, T. and Oakley, P.A. (2011) Functional medicine and chiropractic: A case series in type 2 diabetes mellitus reversal. Clinical Chiropractic, 14, 147148. doi:10.1016/j.clch.2011.09.007

[18] Norman, A.W., Frankel, J.B., Heldt, A.M. and Grodsky, G.M. (1980) Vitamin D deficiency inhibits pancreatic secretion of insulin. Science, 209, 823-825. doi:10.1126/science.6250216

[19] Teegarden, D. and Donkin, S.S. (2009) Vitamin D: Emerging new roles in insulin sensitivity. Nutrition Research Reviews, 22, 82-92. doi:10.1017/S0954422409389301

[20] Peiris, A.N., Bailey, B.A., Peiris, P., Copeland, R.J. and Manning, T. (2011) Race and vitamin D status and monitoring in male veterans. Journal of the National Medical Association, 103, 492-497.

[21] Garret-Mayer, E., Wagner, C.L., Hollis, B.W., Kindy, M.S. and Gattoni-Celli, S. (2012) Vitamin D3 supplemtation (4000 IU/d for 1y) eliminates differences in circulating 25-hydroxyvitamin D between African American and white men. The American Journal of Clinical Nutrition, 96, 332-336. doi:10.3945/ajen.112.034256

[22] NIH (2011) Dietary supplement fact sheet: Vitamin D. http://ods.od.nih.gov/factsheets/VitaminD-QuickFacts/

[23] Gonzalez-Molero, I., Rojo-Martinez, G., Morcillo, S., Gutierrez, C., Rubio, E., Perez-Valero, V., et al. (2013) Hypovitaminosis D and incidence of obesity: A prospective study. European Journal of Nutrition, Epub Ahead of Print. doi:10.1038/ejen.2013.48

[24] Ou, H.Y., Karnchanasorn, R., Lee, L.Z. and Chiu, K.C. (2011) Interaction of BMI with vitamin D and insulin sensitivity. European Journal of Clinical Investigation, 41, 1195-1201. doi:10.1111/j.1365-2362.2011.02525.x

[25] Inzucchi, S.E., Maggs, D.G., Spollett, G.R., Page, S.L., Rife, F.S., Walton, V., et al. (1998) Efficacy and metabolic effects of metformin and troglitazone in type II diabetes mellitus. The New England Journal of Medicine, 338, 867-872. doi:10.1056/NEJM199803263381303

[26] Pittas, A.G., Lau, J., Hu, F.B., and Dawson-Hughes, B. (2007) The role of vitamin D and calcium in type s diabetes. A systematic review and meta-analysis. The Journal of Clinical Endocrinology \& Metabolism, 92, 20172029. doi:10.1210/jc.2007-0298

[27] Boucher, B.J. (1998) Inadequate vitamin D status: Does it contribute to the disorders comprising syndrome " $\mathrm{X}$ "? British Journal of Nutrition, 79, 315-327. 